\title{
Health-related quality of life in current smokers with COPD: factors associated with current smoking and new insights into sex differences
}

This article was published in the following Dove Press journal:

International Journal of COPD

15 September 2016

Number of times this article has been viewed

\author{
Vinay K Cheruvu' \\ Lorriane A Odhiambo' \\ Dana S Mowls² \\ Melissa D Zullo' \\ Abdi T Gudina' \\ 'Department of Biostatistics, \\ Environmental Health Sciences, and \\ Epidemiology, College of Public \\ Health, Kent State University, Kent, \\ $\mathrm{OH},{ }^{2}$ Department of Biostatistics \& \\ Epidemiology, College of Public \\ Health, University of Oklahoma \\ Health Sciences Center, Oklahoma \\ City, OK, USA
}

\begin{abstract}
Findings from studies that examined the association between health-related quality of life (HRQOL) and smoking status among COPD patients have been mixed. Moreover, factors associated with current smoking in COPD patients and differences by sex have not been fully elucidated. Data from the 2011 and 2012 Behavioral Risk Factor Surveillance System was used in this study. Four HRQOL indicators were examined in this study: general health, physical health, mental health, and activity limitations. General health was dichotomized into two groups: "excellent/very good/good" and "fair/poor", and the other three HRQOL indicators were dichotomized into $<14$ (infrequent) and $\geq 14$ (frequent) unhealthy days in the past 30 days. To examine HRQOL indicators in association with current versus former smoking and identify factors associated with current smoking, logistic regression models were used. Sex differences were explored. In COPD patients, current smokers compared to former smokers had significantly poor HRQOL on all subdomains: "fair/ poor" general health (adjusted odds ratio [AOR]: $1.2[95 \%$ confidence interval $\{\mathrm{CI}\}: 1.1-1.5]$ ); poor physical health (AOR: 1.3 [CI: 1.1-1.5]); poor mental health (AOR: 1.8 [CI: 1.4-2.2]); and poor activity limitations (AOR: 1.5 [CI: 1.3-1.9]). HRQOL subdomains affected by current smoking differed by sex except activity limitations. General health (AOR: 1.5 [CI: 1.1-2.0]) and activity limitations (AOR: 1.6 [95\% CI: 1.2-2.2]) in males and physical health (AOR: 1.3 [CI: 1.0-1.6]), mental health (AOR: 2.1 [CI: 1.7-2.6]), and activity limitations (AOR: 1.5 [CI: $1.2-1.9]$ ) in females were significantly impaired due to current smoking. Factors associated with current smoking differed by sex except being unmarried and having less than a college degree, which were associated with current smoking in both males and females. These findings have important implications for health care providers in designing more effective interventions which tailor to and target specific subgroups for smoking cessation.
\end{abstract}

Keywords: health-related quality of life, HRQOL, COPD, smoking, current smokers, former smokers, BRFSS

\section{Introduction}

Chronic obstructive pulmonary disease (COPD), including emphysema and chronic bronchitis, is a serious, progressive lung disease characterized by obstruction of air flow that interferes with normal breathing and results in symptoms, such as wheezing, shortness of breath, chronic cough, and tightness of chest. ${ }^{1}$ COPD is the third leading cause of death in the US after cancer and heart disease and continues to be a significant contributor to morbidity and mortality. ${ }^{2-4}$ Adults with COPD experience higher rates of comorbidities, such as anxiety, depression, diabetes, and cardiovascular diseases, and are more likely to report poor health-related quality of life (HRQOL) when compared
Correspondence: Vinay K Cheruvu Department of Biostatistics, Environmental Health Sciences, and Epidemiology, College of Public Health, Hilltop Drive, 320 Lowry Hall, Kent State University, Kent, $\mathrm{OH} 44242$, USA

$\mathrm{Tel}+\mathrm{I} 3306726518$

Fax +I 3306726505

Email vcheruvu@kent.edu 
to adults without COPD in the general population. ${ }^{5-8}$ The costs associated with COPD are a major economic burden in the US. ${ }^{9}$ According to a recent study by the Centers for Disease Control and Prevention, the direct and indirect costs will rise from $\sim \$ 32$ billion a year in 2010 to $\sim \$ 49$ billion annually by $2020 .^{10}$

Although nonsmoking-related factors, such as environmental, occupational, and genetic predisposition, cause COPD, cigarette smoking continues to be a major risk factor for COPD, accounting for as many as nine out of ten COPD-related deaths. ${ }^{11-17}$ In a recent study using data from the 2011 Behavioral Risk Factor Surveillance System (BRFSS), nearly half (47.3\%) of adults with COPD were current smokers compared to $20 \%$ of adults with no chronic conditions who were current smokers. Further, among the current smokers with COPD, $\sim 40 \%$ did not make an attempt to quit smoking during the past year. ${ }^{18}$ This is particularly concerning because of the smoking-associated decline in lung function that affects the burden of COPD and results in poor quality of life. ${ }^{19-22}$ According to the Global initiative for chronic Obstructive Lung Disease guidelines, smoking cessation is the key intervention for all COPD patients who are current smokers. Smoking cessation can prevent COPD exacerbations and improve health status. ${ }^{23}$

HRQOL is a multidimensional construct comprising an individual's subjective evaluation of general, physical, emotional, and social aspects of health and well-being. ${ }^{24,25}$ It is increasingly used by clinicians and researchers as an outcome of interest in patients with COPD and other chronic conditions, as it provides the patients perspective on their health status. To date, several studies conducted in the US have documented the association between COPD and HRQOL by comparing the HRQOL of COPD patients with the general population. ${ }^{6-8}$ While some studies conducted outside of the US examined the association between HRQOL and COPD severity, ${ }^{26-28}$ other studies examined the association between smoking cessation and HRQOL. ${ }^{22,26,29-31}$ Recently, a study by Galaznik et al examined the burden of smoking on quality of life in patients with COPD using national data from the 2009/2010 US National Health and Wellness Survey. ${ }^{22}$ However, the findings from these studies have been mixed. For example, the study by Stahl et al reports no significant difference in HRQOL by smoking status, ${ }^{26}$ while other studies reported significant differences in HRQOL by smoking status. ${ }^{30,31}$ Moreover, the factors associated with current smoking in COPD patients and any differences by sex have not been fully elucidated.

To better understand the HRQOL in current smokers versus former smokers among COPD patients diagnosed by spirometry and identify the sociodemographic characteristics and other factors associated with current smoking, the current study used data from the 2011 and 2012 BRFSS, a large national sample of US adults living with COPD. Identifying the characteristics of current smokers with COPD may help health care providers design more effective behavioral interventions which tailor to and target specific subgroups for smoking cessation.

\section{Methods}

\section{General study design and population}

The BRFSS is a federally funded telephone survey designed and conducted annually by the Centers for Disease Control and Prevention in collaboration with state health departments in all 50 states, District of Columbia; Puerto Rico; the US Virgin Islands; and Guam. The survey collects data on health conditions, preventive health practices, and risk behaviors of the adults selected. ${ }^{32}$ The BRFSS methods, sample selection, including the weighting procedure and technical information, are described elsewhere. ${ }^{33,34}$ All BRFSS questionnaires, data, and reports are available at http://www.cdc.gov/brfss/. Data for this study were obtained from the 2011 and 2012 BRFSS landline and cell phone data. In 2011, 21 states, including District of Columbia, and Puerto Rico, and in 2012, 13 states administered the optional BRFSS COPD module.

\section{COPD}

In the 2011 and 2012 BRFSS annual surveys, all individuals were asked the core question about their history of COPD. Individuals with an affirmative response to the question "Has a doctor, nurse, or other health professional EVER told that you have chronic obstructive pulmonary disease (COPD), emphysema or chronic bronchitis?" were identified as having COPD $(n=22,633)$. Of these, 16,602 individuals reported being given a breathing test, such as spirometry, to diagnose COPD.

\section{Current smokers versus former smokers}

Smoking status was identified using the four-level smoker status variable provided in the BRFSS data. Current smoker was defined as someone who smoked at least 100 cigarettes in his or her entire life and who currently smokes every day or some days. Former smoker was defined as having smoked at least 100 cigarettes in his or her entire life and currently never smokes. Never smoker was defined as not having smoked at least 100 cigarettes in his or her entire life. For the purposes of this study, the sample was restricted to individuals who were either current or former smokers $(n=12,926)$. 


\section{HRQOL}

Four HRQOL indicators were examined in this study: general health, physical health, mental health, and activity limitations. General health was assessed by asking participants to rate their overall health. Possible responses were "excellent", "very good", "good", "fair", or "poor". The responses were dichotomized into two groups: "excellent/very good/good" and "fair/poor". Physical health, mental health, and activity limitations were assessed by asking participants to self-rate their health in the past 30 days: "Now thinking about your physical health, which includes physical illness and injury, for how many days during the past 30 days was your physical health not good?" (physical health); "Now thinking about your mental health, which includes stress, depression, and problems with emotions, for how many days during the past 30 days was your mental health not good?" (mental health); and "During the past 30 days, for about how many days did poor physical or mental health keep you from doing your usual activities, such as self-care, or recreation?" (activity limitations). Responses were dichotomized into $<14$ (infrequent) and $\geq 14$ (frequent) unhealthy days for each indicator. The dichotomy of the HRQOL responses has been widely used in several studies using the BRFSS data. ${ }^{24,35}$ The HRQOL questions have been shown to have validity and reliability for population-based studies. ${ }^{36}$

\section{Sociodemographic factors and covariates of interest}

Sociodemographic variables: age, sex, ethnicity, marital status, education, employment, binge drinking, and exercise and covariates: number of comorbidities, having a health plan, having a primary care provider, routine checkup, not seeing a doctor due to cost, visiting a doctor about shortness of breath, quality of life affected due to shortness of breath, been to the emergency room for COPD, and taking medications for COPD were considered in this study. Of the 12,926 individuals, 1,963 were excluded due to missing data on at least one of the variables considered in this study. This resulted in 10,963 participants with complete data.

\section{Statistical analysis}

Primary analysis examined the HRQOL indicators in association with smoking status. A secondary analysis identified the sociodemographic characteristics associated with current smoking status. A stratified analysis was conducted by sex to examine potential sex differences with respect to the association between smoking status and HRQOL and sociodemographic characteristics. Sampling weights provided in the 2011 and 2012 BRFSS public-use data that adjust for unequal selection probabilities, survey nonresponse, and oversampling were used to account for the complex sampling design and obtain population-based estimates which reflect US noninstitutionalized adults.

To describe the characteristics of the study population, weighted prevalence estimates and corresponding 95\% confidence intervals (CIs) were computed. Logistic regression models were used to estimate the unadjusted and adjusted prevalence odds ratios and 95\% CI in both analyses. Adjusted analyses included age in years, sex, ethnicity, marital status, level of education, employment status, number of other chronic conditions, physical activity, binge drinking, health care access and utilization, and COPD-related factors (if quality of life was affected by shortness of breath, emergency room visit or hospitalization, visit to a doctor for shortness of breath, and if on COPD medications). All analyses were conducted in SAS 9.3 (SAS Institute Inc., Cary, NC, USA) using SAS survey procedures (PROC SURVEYFREQ, PROC SURVEYMEANS, PROC SURVEYLOGISTIC) to account for the complex sampling design. A two-sided $P$-value $<0.05$ was considered statistically significant.

\section{Results}

\section{Sample characteristics}

Of the 16,602 individuals with COPD diagnosed by taking a breathing test, such as spirometry, $39.8 \%$ (95\% CI: $38.3 \%-41.4 \%)$ were former smokers $(\mathrm{n}=7,572)$ and $37.9 \%$ (95\% CI: $36.3 \%-39.5 \%)$ were current smokers $(n=5,354)$. Table 1 describes the characteristics of former and current smokers with complete data $(n=10,963)$, weighted prevalence estimates, and corresponding 95\% CI, overall and by smoking status. At the time of the survey, the average age of all adults in this study was 58.5 years, $53.3 \%$ were female, $80.1 \%$ were White non-Hispanic, and $52.7 \%$ were single. Only $10.7 \%$ of participants were college graduates and $24.2 \%$ employed. Eleven percent of those with COPD were binge drinkers, $57.0 \%$ exercised, and $72.2 \%$ had one or more chronic conditions. And, $88.0 \%$ had a health plan, $90.3 \%$ had a primary care provider, $66.9 \%$ took medications for COPD, $47.2 \%$ visited a doctor due to shortness of breath, $70.4 \%$ reported shortness of breath affecting their quality of life, $18.6 \%$ had been to the emergency room or hospital for COPD, 78.5\% had a routine checkup within the year, and $24.1 \%$ did not see a doctor due to medical cost. The prevalence of current smoking was $47.9 \%$ in males and $49.7 \%$ in females.

Compared to former smokers, current smokers were significantly younger ( 52.4 vs 64.3 years), were more likely 
Table I Characteristics of adults with COPD and their smoking status $(n=10,963)$

\begin{tabular}{|c|c|c|c|c|}
\hline \multirow[t]{2}{*}{ Characteristics } & \multirow{2}{*}{$\begin{array}{l}\text { Unweighted } \\
n\end{array}$} & \multirow{2}{*}{$\begin{array}{l}\text { Overall mean or } \\
\text { proportion }(95 \% \mathrm{Cl})\end{array}$} & \multicolumn{2}{|l|}{ Smoking status } \\
\hline & & & $\begin{array}{l}\text { Current }(n=4,576) \\
\text { mean or proportion } \\
(95 \% \mathrm{CI})\end{array}$ & $\begin{array}{l}\text { Former }(n=6,387) \\
\text { mean or proportion } \\
(95 \% \mathrm{Cl})\end{array}$ \\
\hline \multicolumn{5}{|l|}{ Sociodemographics } \\
\hline Age & 10,963 & $58.5(57.8-59.2)$ & $52.4(51.5-53.3)$ & $64.3(63.3-65.3)$ \\
\hline \multicolumn{5}{|l|}{ Sex } \\
\hline Male & 4,154 & $46.7(44.7-48.6)$ & $45.7(42.8-48.7)$ & $47.6(45.0-50.1)$ \\
\hline Female & 6,809 & $53.3(51.4-55.3)$ & $54.3(51.3-57.2)$ & $52.4(49.9-55.0)$ \\
\hline \multicolumn{5}{|l|}{ Ethnicity } \\
\hline White non-Hispanic & 9,264 & $80.1(78.3-81.9)$ & $78.4(75.7-81.0)$ & $81.7(79.3-84.2)$ \\
\hline Black non-Hispanic & 767 & $8.7(7.4-10.0)$ & $10.7(8.6-12.9)$ & $6.8(5.4-8.2)$ \\
\hline Hispanic & 278 & $4.5(3.5-5.5)$ & $4.4(3.1-5.7)$ & $4.7(3.3-6.1)$ \\
\hline Others ${ }^{\mathrm{a}}$ & 654 & $6.7(5.5-7.9)$ & $6.5(5.1-8.0)$ & $6.8(4.9-8.7)$ \\
\hline \multicolumn{5}{|l|}{ Marital status } \\
\hline Married & 4,530 & $47.2(45.3-49.2)$ & $41.7(38.9-44.6)$ & $52.5(50.0-55.0)$ \\
\hline Unmarried ${ }^{\mathrm{b}}$ & 6,433 & $52.8(50.8-54.7)$ & $58.3(55.4-61.1)$ & $47.5(45.0-50.0)$ \\
\hline \multicolumn{5}{|l|}{ Education } \\
\hline Elementary/high school/some college & 9,105 & $89.4(88.4-90.3)$ & $93.1(91.9-94.2)$ & $85.8(84.4-87.2)$ \\
\hline College graduate & $\mathrm{I}, 858$ & $10.6(9.7-11.6)$ & $6.9(5.8-8.1)$ & $14.2(12.8-15.6)$ \\
\hline \multicolumn{5}{|l|}{ Employment } \\
\hline Employed & 2,033 & $24.2(22.4-26.1)$ & $28.5(25.7-31.2)$ & $20.2(17.6-22.8)$ \\
\hline Unemployedc & 8,930 & $75.8(73.9-77.6)$ & $71.5(68.8-74.3)$ & $79.8(77.2-82.4)$ \\
\hline \multicolumn{5}{|l|}{ Exercise } \\
\hline Yes & 5,928 & $57.0(55.1-58.8)$ & $57.3(54.5-60.0)$ & $56.7(54.3-59.1)$ \\
\hline No & 5,035 & $43.0(41.2-44.9)$ & $42.7(40.0-45.5)$ & $43.3(40.9-45.7)$ \\
\hline \multicolumn{5}{|l|}{ Binge drinking } \\
\hline Yes & 909 & $11.4(10.1-12.6)$ & $15.5(13.4-17.7)$ & $7.4(6.3-8.6)$ \\
\hline No & 10,054 & $88.6(87.4-89.9)$ & $84.5(82.3-86.6)$ & $92.6(91.4-93.7)$ \\
\hline \multicolumn{5}{|l|}{ Number of chronic conditions } \\
\hline 0 & 2,875 & $27.8(25.9-29.6)$ & $29.8(27.2-32.3)$ & $25.9(23.3-28.5)$ \\
\hline 1 & 3,932 & $36.1(34.3-38.0)$ & $37.0(34.3-39.8)$ & $35.3(33.0-37.6)$ \\
\hline$\geq 2$ & 4,156 & $36.1(34.3-37.9)$ & $33.2(30.5-36)$ & $38.8(36.4-41.3)$ \\
\hline \multicolumn{5}{|l|}{ Having a health plan } \\
\hline Yes & 10,054 & $88.0(86.5-89.4)$ & $81.4(78.8-83.9)$ & $94.3(93.1-95.5)$ \\
\hline No & 909 & $12.0(10.6-13.5)$ & $18.6(\mid 6.1-21.2)$ & $5.7(4.5-6.9)$ \\
\hline \multicolumn{5}{|l|}{ Having a primary care provider } \\
\hline Yes & 10,294 & $90.3(88.7-91.8)$ & $85.0(82.4-87.5)$ & $95.4(93.6-97.1)$ \\
\hline No & 669 & $9.7(8.2-11.3)$ & $15.0(12.5-17.6)$ & $4.6(2.9-6.4)$ \\
\hline \multicolumn{5}{|c|}{ Did not see a doctor in the past 12 months due to medical cost } \\
\hline Yes & 2,007 & $24.1(22.3-25.9)$ & $32.7(29.8-35.6)$ & $15.9(\mid 3.9-17.9)$ \\
\hline No & 8,956 & $75.9(74.1-77.7)$ & $67.3(64.5-70.2)$ & $84.1(82.1-86.1)$ \\
\hline \multicolumn{5}{|l|}{ Annual checkup } \\
\hline Yes & 9,073 & $78.5(76.6-80.3)$ & $72.2(69.4-75.0)$ & $84.5(82.3-86.7)$ \\
\hline No & $\mathrm{I}, 890$ & $21.5(19.7-23.4)$ & $27.8(25.0-30.6)$ & $15.5(\mid 3.3-17.7)$ \\
\hline \multicolumn{5}{|l|}{ Shortness of breath affects quality of life } \\
\hline Yes & 7,734 & $70.4(68.6-72.2)$ & $71.0(68.3-73.6)$ & $69.9(67.6-72.1)$ \\
\hline No & 3,229 & $29.6(27.8-31.4)$ & $29.0(26.4-31.7)$ & $30.1(27.9-32.4)$ \\
\hline \multicolumn{5}{|c|}{ Seen a doctor in the past 12 months for symptoms related shortness of breath, bronchitis, or other COPD, or emphysema flare } \\
\hline Yes & 5,248 & $47.2(45.3-49.2)$ & $44.3(41.4-47.1)$ & $50.1(47.5-52.6)$ \\
\hline No & 5,715 & $52.8(50.8-54.7)$ & $55.7(52.8-58.6)$ & $49.9(47.4-52.5)$ \\
\hline Visited an emergency room or was admi & to the hospital i & past 12 months because & OPD, chronic bronchitis, & mphysema \\
\hline Yes & I,937 & $18.6(17.1-20.2)$ & $19.2(\mid 6.7-21.6)$ & $18.1(\mid 6.2-20.1)$ \\
\hline No & 9,026 & $81.4(79.8-82.9)$ & $80.8(78.4-83.3)$ & $81.9(79.9-83.8)$ \\
\hline Takes medications each day to help with & & & & \\
\hline Yes & 7,648 & $66.9(65.0-68.8)$ & $63.4(60.6-66.2)$ & $70.2(67.7-72.8)$ \\
\hline No & 3,315 & $33.1(31.2-35.0)$ & $36.6(33.7-39.4)$ & $29.8(27.2-32.3)$ \\
\hline
\end{tabular}




\begin{tabular}{|c|c|c|c|c|}
\hline & \multirow{2}{*}{$\begin{array}{l}\text { Unweighted } \\
\text { n }\end{array}$} & \multirow{2}{*}{$\begin{array}{l}\text { Overall mean or } \\
\text { proportion }(95 \% \mathrm{Cl})\end{array}$} & \multicolumn{2}{|l|}{ Smoking status } \\
\hline & & & $\begin{array}{l}\text { Current }(n=4,576) \\
\text { mean or proportion } \\
(95 \% \mathrm{Cl})\end{array}$ & $\begin{array}{l}\text { Former }(n=6,387) \\
\text { mean or proportion } \\
(95 \% \mathrm{Cl})\end{array}$ \\
\hline \multicolumn{5}{|c|}{ Health-related quality of life } \\
\hline \multicolumn{5}{|l|}{ General health } \\
\hline Excellent/very good/good & 4,668 & $43.1(41.1-45.0)$ & $40.4(37.5-43.3)$ & $45.7(43.1-48.3)$ \\
\hline Fair/poor & 6,295 & $56.9(55.0-58.9)$ & $59.6(56.7-62.5)$ & $54.3(51.7-56.9)$ \\
\hline \multicolumn{5}{|c|}{ Frequent days of poor physical health } \\
\hline $0-13$ days & 6,185 & $55.0(53.1-57.0)$ & $51.7(48.8-54.6)$ & $58.2(55.8-60.7)$ \\
\hline $14-30$ days & 4,778 & $45.0(43.0-46.9)$ & $48.3(45.4-5 \mid .2)$ & $41.8(39.3-44.2)$ \\
\hline \multicolumn{5}{|c|}{ Frequent days of poor mental health } \\
\hline $0-13$ days & 8,156 & $69.0(67.1-70.8)$ & $58.6(55.8-61.4)$ & $78.9(76.7-8 I .1)$ \\
\hline 14-30 days & 2,807 & $31.0(29.2-32.9)$ & $41.4(38.6-44.2)$ & $21.1(18.9-23.3)$ \\
\hline \multicolumn{5}{|c|}{ Frequent days of poor activity limitations } \\
\hline $0-13$ days & 7,572 & $67.1(65.3-68.9)$ & $61.3(58.5-64.1)$ & $72.6(70.5-74.8)$ \\
\hline 14-30 days & 3,391 & $32.9(31.1-34.7)$ & $38.7(35.9-41.5)$ & $27.4(25.2-29.5)$ \\
\hline
\end{tabular}

Notes: a Others includes Asian non-Hispanic, American Indian/Alaskan Native non-Hispanic, and other race non-Hispanic. bUnmarried includes divorced/widowed/separated/ never married/member of an unmarried couple. 'Unemployed includes out of work, homemaker or student, retired, unable to work.

Abbreviation: $\mathrm{Cl}$, confidence interval.

to: have been divorced, separated, widowed, or never married (58.3\% vs $47.5 \%)$, have less than college education $(93.1 \%$ vs $85.8 \%$ ), report binge drinking ( $15.5 \%$ vs $7.4 \%)$, not have a health plan (18.6\% vs 5.7\%), not have a primary care physician (15.0\% vs 4.6\%), not be taking medications for COPD (36.6\% vs $29.8 \%$ ), and were less likely to have seen a doctor about shortness of breath (44.3\% vs $50.0 \%)$.

\section{HRQOL}

About $57 \%$ of adults with COPD reported "fair/poor" general health and $45 \%, 31 \%$, and $33 \%$ reported frequent days of poor physical health, poor mental health, and poor activity limitations correspondingly. Compared to former smokers, current smokers reported significantly higher proportions of frequent days of poor physical health (48.3\% vs $41.8 \%$ ), poor mental health $(41.4 \%$ vs $21.1 \%)$, and poor activity limitations (38.7\% vs $27.4 \%$ ). "Fair/poor" general health was marginally significant between former and current smokers (Table 1).

\section{Model-based prevalence odds ratios for HRQOL among current smokers}

Tables 2 and 3 present the model-based unadjusted and adjusted odds ratios (AOR) and corresponding 95\% CIs for poor HRQOL in current smokers compared to former smokers with COPD. Overall, current smokers with COPD had significantly poor HRQOL on all four indicators: "fair/poor" general health (AOR: 1.2 [95\% CI: 1.1-1.5]); poor physical health (AOR: 1.3 [95\% CI: 1.1-1.5]); poor mental health
(AOR: 1.8 [95\% CI: 1.4-2.2]); and poor activity limitations (AOR: 1.5 [95\% CI: 1.3-1.9]). When stratified by sex, males who are current smokers had significantly "fair/poor" general health (AOR: 1.5 [95\% CI: 1.1-2.0]) and poor activity limitations (AOR: 1.6 [95\% CI: 1.2-2.2]), when compared to males who are former smokers. Among females, current smokers had significantly poor physical health (AOR: 1.3 [95\% CI: 1.0-1.6]); poor mental health (AOR: 2.1 [95\% CI: 1.7-2.6]);

Table 2 Estimated prevalence odds ratios and $95 \% \mathrm{Cl}$ for healthrelated quality of life: general health and physical health

\begin{tabular}{|c|c|c|c|c|}
\hline \multirow[t]{2}{*}{ Smoking status } & \multicolumn{2}{|c|}{$\begin{array}{l}\text { "Fair/poor" general } \\
\text { health }\end{array}$} & \multicolumn{2}{|c|}{$\begin{array}{l}\text { 14-30 days of poor } \\
\text { physical health }\end{array}$} \\
\hline & $\begin{array}{l}\text { UOR } \\
(95 \% \mathrm{Cl})\end{array}$ & $\begin{array}{l}\text { AOR } \\
(95 \% \mathrm{Cl})\end{array}$ & $\begin{array}{l}\text { UOR } \\
(95 \% \mathrm{Cl})\end{array}$ & $\begin{array}{l}\text { AOR } \\
(95 \% \mathrm{Cl})\end{array}$ \\
\hline \multicolumn{5}{|l|}{ All $(n=10,963)$} \\
\hline Cur & $\begin{array}{l}1.2 \\
(1.1-1.5)\end{array}$ & $\begin{array}{l}1.2 \\
(1.0-1.5)\end{array}$ & $\begin{array}{l}1.3 \\
(1.1-1.5)\end{array}$ & $\begin{array}{l}1.3 \\
(1.0-1.5)\end{array}$ \\
\hline Former & Reference & Reference & Reference & Reference \\
\hline \multicolumn{5}{|l|}{ Males $(n=4,154)$} \\
\hline Current & $\begin{array}{l}1.2 \\
(1.0-1.6)\end{array}$ & $\begin{array}{l}1.5 \\
(1.1-2.0)\end{array}$ & $\begin{array}{l}1.2 \\
(0.9-1.6)\end{array}$ & $\begin{array}{l}1.2 \\
(0.9-1.6)\end{array}$ \\
\hline Former & Reference & Reference & Reference & Reference \\
\hline \multicolumn{5}{|l|}{ Females $(n=6,809)$} \\
\hline Current & $\begin{array}{l}1.2 \\
(1.0-1.5)\end{array}$ & $\begin{array}{l}1.1 \\
(0.9-1.4)\end{array}$ & $\begin{array}{l}1.4 \\
(1.1-1.7)\end{array}$ & $\begin{array}{l}1.3 \\
(1.0-1.6)\end{array}$ \\
\hline Former & Reference & Reference & Reference & Reference \\
\hline
\end{tabular}

Notes: Adjusted for age, sex, ethnicity, marital status, education, employment, chronic conditions, physical activity, binge drinking, health care access and utilization, and COPD-related factors. AOR for males and females was adjusted for all covariates except sex. Significance $(P=0.5)$ is shown in bold.

Abbreviations: $\mathrm{AOR}$, adjusted odds ratio; $\mathrm{Cl}$, confidence interval; $\mathrm{UOR}$, unadjusted odds ratio. 
Table 3 Estimated prevalence odds ratios and $95 \% \mathrm{Cl}$ for healthrelated quality of life: mental health and activity limitations

\begin{tabular}{|c|c|c|c|c|}
\hline \multirow[t]{2}{*}{$\begin{array}{l}\text { Smoking } \\
\text { status }\end{array}$} & \multicolumn{2}{|c|}{$\begin{array}{l}\text { 14-30 days of poor } \\
\text { mental health }\end{array}$} & \multicolumn{2}{|c|}{$\begin{array}{l}\text { 14-30 days of poor } \\
\text { activity limitations }\end{array}$} \\
\hline & $\begin{array}{l}\text { UOR } \\
(95 \% \mathrm{Cl})\end{array}$ & $\begin{array}{l}\text { AOR } \\
(95 \% \mathrm{Cl})\end{array}$ & $\begin{array}{l}\text { UOR } \\
(95 \% \mathrm{Cl})\end{array}$ & $\begin{array}{l}\text { AOR } \\
(95 \% \mathrm{Cl})\end{array}$ \\
\hline \multicolumn{5}{|c|}{ All $(n=10,963)$} \\
\hline Current & $\begin{array}{l}2.6 \\
(2.2-3.2)\end{array}$ & $\begin{array}{l}1.8 \\
(1.4-2.2)\end{array}$ & $\begin{array}{l}1.7 \\
(1.4-2.0)\end{array}$ & $\begin{array}{l}1.5 \\
(1.3-1.9)\end{array}$ \\
\hline Former & Reference & Reference & Reference & Reference \\
\hline \multicolumn{5}{|c|}{ Males $(n=4,154)$} \\
\hline Current & $\begin{array}{l}2.3 \\
(1.6-3.1)\end{array}$ & $\begin{array}{l}1.3 \\
(0.9-2.0)\end{array}$ & $\begin{array}{l}1.7 \\
(1.3-2.2)\end{array}$ & $\begin{array}{l}1.6 \\
(1.2-2.2)\end{array}$ \\
\hline Former & Reference & Reference & Reference & Reference \\
\hline \multicolumn{5}{|c|}{ Females $(n=6,809)$} \\
\hline Current & $\begin{array}{l}3.0 \\
(2.4-3.6)\end{array}$ & $\begin{array}{l}2.1 \\
(1.7-2.6)\end{array}$ & $\begin{array}{l}1.7 \\
(1.4-2.0)\end{array}$ & $\begin{array}{l}1.5 \\
(1.2-1.9)\end{array}$ \\
\hline Former & Reference & Reference & Reference & Reference \\
\hline
\end{tabular}

Notes: Adjusted for age, sex, ethnicity, marital status, education, employment, chronic conditions, physical activity, binge drinking, health care access and utilization, and COPD-related factors. AOR for males and females was adjusted for all covariates except sex. Significance $(P=0.5)$ is shown in bold.

Abbreviations: $\mathrm{AOR}$, adjusted odds ratio; $\mathrm{Cl}$, confidence interval; $\mathrm{UOR}$, unadjusted odds ratio.

and poor activity limitations (AOR: 1.5 [95\% CI: 1.2-1.9]), compared to females who are former smokers.

\section{Factors associated with current smoking among individuals with COPD}

Table 4 presents the model-based unadjusted and adjusted odds ratios and corresponding $95 \%$ CIs for factors associated with current smoking among all individuals with COPD and by sex. When compared to former smokers, current smokers were more likely to be single (AOR: 1.5 [95\% CI: 1.2-1.8]), have less than a college education (AOR: 2.0 [95\% CI: 1.5-2.5]), report binge drinking (AOR: 1.5 [95\% CI: 1.1-2.0]), report no physical activity (AOR: 1.2 [95\% CI: 1.0-1.4]), have no health plan (AOR: 1.6 [95\% CI: 1.1-2.3]), and to have not been to a doctor for shortness of breath (AOR: 1.4 [95\% CI: 1.1-1.7]). Age was inversely related with current smoking. There was no association with race. Although sex was not associated with current smoking, when stratified by sex, marital status, and education were significantly associated with current smoking in both males and females. Married adults and college graduates were less likely to be current smokers. Additionally, in males, being unemployed, binge drinking, and not having a health plan were associated with current smoking. In females, no physical activity was significantly associated with current smoking.

\section{Discussion}

Smoking is a major public health problem among COPD patients as it comprises patients' overall health and quality of life and impacts the health care system. This study has three important findings:

1. First, this study confirms results from a previous study by Galaznik et al which reported poorer HRQOL among COPD patients who currently smoke compared to former smokers. ${ }^{22}$ The difference between the study by Galaznik et al and the current study is that former smokers were defined as those who had quit $>10$ years prior to when the survey was administered. The researchers also found that current smokers and those who quit smoking for 10 years or less had similar HRQOL. As data on duration of smoking cessation among former smokers were not available in the current study, former smokers were defined as having smoked at least 100 cigarettes in their entire life but currently do not smoke. Therefore, our findings suggest current smoking may have a stronger effect on poor HRQOL than reported previously. Also, the current study findings are contrary to the reasoning that current smokers might have COPD that is less severe than former smokers and therefore HRQOL may be better in current smokers. ${ }^{37}$ This is evidenced by the finding that current smokers reported impaired HRQOL on all four domains. In a recent study by Paap et al, physical health and social health (activity limitations) emerged as important subdomains of HRQOL in patients with COPD..$^{38}$ This further reinforces the importance of smoking cessation in patients with COPD to help improve their overall quality of life.

2. Second, this study identified the subdomains of HRQOL most affected by current smoking across sex in COPD patients diagnosed by a breathing test. General health and activity limitations in males and physical health, mental health, and activity limitations in females were significantly impaired due to current smoking. A possible explanation for sex differences in impaired HRQOL with females experiencing more subdomains of impaired HRQOL than males may be because females may be more susceptible to the detrimental effects of smoking. ${ }^{39}$

3. Third, this study identified the sociodemographic characteristics of current smokers and how those differed across sex. Consistent with previous findings, ${ }^{22}$ this study identified that current smokers were more likely to be single/unmarried, have less than a college education, not exercise, binge drinking, and not have a health 
Table 4 Estimated prevalence OR and $95 \% \mathrm{Cl}$ for current smoking $(n=10,963)$

\begin{tabular}{|c|c|c|c|}
\hline Characteristics & $\begin{array}{l}\text { Overall } \\
\text { OR }(95 \% \mathrm{Cl})\end{array}$ & $\begin{array}{l}\text { Males } \\
\text { OR }(95 \% \mathrm{Cl})\end{array}$ & $\begin{array}{l}\text { Females } \\
\text { OR }(95 \% \mathrm{Cl})\end{array}$ \\
\hline \multicolumn{4}{|l|}{ Sociodemographics } \\
\hline Age (in years) & $0.9(0.9-1.0)$ & $0.9(0.9-0.96)$ & $0.9(0.9-1.0)$ \\
\hline \multicolumn{4}{|l|}{ Sex } \\
\hline Female & Reference & & \\
\hline Male & $1.0(0.8-1.2)$ & - & - \\
\hline \multicolumn{4}{|l|}{ Ethnicity } \\
\hline White non-Hispanic & Reference & Reference & Reference \\
\hline Black non-Hispanic & $1.2(0.8-1.8)$ & $1.7(0.9-3.4)$ & $0.9(0.6-1.3)$ \\
\hline Hispanic & $0.6(0.4-1.1)$ & $0.5(0.2-1.1)$ & $0.7(0.4-1.4)$ \\
\hline Others $^{\mathrm{a}}$ & $0.8(0.5-1.3)$ & $0.9(0.5-1.9)$ & $0.8(0.4-1.3)$ \\
\hline \multicolumn{4}{|l|}{ Marital status } \\
\hline Married & Reference & Reference & Reference \\
\hline Unmarried $^{\mathrm{b}}$ & $1.5(I .2-1.8)$ & $1.5(I . I-2 . I)$ & $1.4(I . I-I .7)$ \\
\hline \multicolumn{4}{|l|}{ Education } \\
\hline College graduate & Reference & Reference & Reference \\
\hline Elementary/high school/some college & $2.0(1.5-2.5)$ & $1.7(1.3-2.4)$ & $2.1(1.5-3.0)$ \\
\hline \multicolumn{4}{|l|}{ Employment } \\
\hline Employed & Reference & Reference & Reference \\
\hline Unemployed ${ }^{c}$ & I.I (0.9-I.5) & $1.6(1.1-2.4)$ & $0.9(0.7-1.2)$ \\
\hline \multicolumn{4}{|l|}{ Exercise } \\
\hline Yes & Reference & Reference & Reference \\
\hline No & $1.2(1.0-1.4)$ & I.I (0.8-I.5) & $1.2(1.0-1.5)$ \\
\hline \multicolumn{4}{|l|}{ Binge drinking } \\
\hline No & Reference & Reference & Reference \\
\hline Yes & $1.5(1.1-2.0)$ & $1.8(1.2-2.9)$ & I.I (0.8-1.6) \\
\hline \multicolumn{4}{|l|}{ Number of chronic conditions } \\
\hline 0 & Reference & Reference & Reference \\
\hline 1 & $1.0(0.8-1.4)$ & I.I (0.7-I.7) & $1.0(0.7-1.3)$ \\
\hline$\geq 2$ & I.I (0.8-I.4) & I.I (0.7-I.7) & I.0 (0.7-I.3) \\
\hline \multicolumn{4}{|l|}{ Having a health plan } \\
\hline Yes & Reference & Reference & Reference \\
\hline No & $1.6(1.1-2.3)$ & $2.8(1.5-5.0)$ & I.I (0.8-1.7) \\
\hline \multicolumn{4}{|l|}{ Having a primary care provider } \\
\hline Yes & Reference & Reference & Reference \\
\hline No & I.I (0.7-I.9) & I.I (0.5-2.5) & I.I (0.7-I.8) \\
\hline \multicolumn{4}{|c|}{ Did not see a doctor in the past 12 months due to medical cost } \\
\hline Yes & Reference & Reference & Reference \\
\hline No & $0.0(0.6-1.1)$ & $0.9(0.5-1.3)$ & $0.8(0.6-1.0)$ \\
\hline \multicolumn{4}{|l|}{ Annual checkup } \\
\hline Yes & Reference & Reference & Reference \\
\hline No & I.I $(0.9-1.5)$ & $1.0(0.7-1.6)$ & $1.2(0.9-1.6)$ \\
\hline \multicolumn{4}{|l|}{ Shortness of breath affects quality of life } \\
\hline No & Reference & Reference & Reference \\
\hline Yes & $0.9(0.7-1.2)$ & $0.8(0.6-1.2)$ & $1.0(0.8-1.2)$ \\
\hline \multicolumn{4}{|c|}{ Seen a doctor in the past 12 months for symptoms related shortness of breath, bronchitis, or other COPD, or emphysema flare } \\
\hline Yes & Reference & Reference & Reference \\
\hline No & $1.4(I .1-1.7)$ & I.2 (0.8-1.7) & $1.6(1.3-2.0)$ \\
\hline \multicolumn{4}{|c|}{ Visited an emergency room or was admitted to the hospital in the past 12 months because of COPD, chronic bronchitis, or emphysema } \\
\hline Yes & Reference & Reference & Reference \\
\hline No & I.I (0.8-I.4) & $1.3(0.8-2.0)$ & $0.9(0.7-1.2)$ \\
\hline \multicolumn{4}{|c|}{ Takes medications each day to help with COPD } \\
\hline Yes & Reference & Reference & Reference \\
\hline No & $1.0(0.8-1.2)$ & I.0 (0.7-I.4) & $0.9(0.7-1.2)$ \\
\hline
\end{tabular}


plan. When stratified by sex, being single/unmarried and having less than a college education were predictors of current smoking in both males and females. In addition, unemployment, binge drinking, and not having a health plan in males and no physical activity (exercise) in females were significant predictors of current smoking. To our knowledge, this is the first study, using national data, to report sociodemographic factors associated with current smoking across sex in patients with COPD. In a recent study by Lou et al, smoking abstinence rates were significantly higher in participants receiving behavioral intervention than those receiving usual care. ${ }^{40}$ The sociodemographic characteristics identified in this study across sex will help design effective behavioral interventions for smoking cessation.

Although this study has strengths and important findings, it is acknowledged that it has some limitations. First, the cross-sectional nature of the BRFSS data prevents interpretations about the temporal sequence of the association between current smoking and poor HRQOL. Second, BRFSS data are based on self-report and therefore may be subject to recall-bias for certain types of responses. Finally, the duration of current smoking, duration of smoking cessation among former smokers, and the COPD severity or treatment were not available in the BRFSS data for inclusion in the analysis.

\section{Conclusion}

In summary, these findings confirm that in COPD patients diagnosed with spirometry, current smoking was significantly associated with poorer HRQOL. The subdomains of HRQOL most affected by current smoking differed by sex except activity limitations, which was affected in both males and females. The sociodemographic factors associated with current smoking also differed by sex except being unmarried and having less than a college degree, which were also associated with current smoking in both males and females. These findings have important implications for the health care providers in helping them design more effective behavioral interventions which tailor to and target specific subgroups for smoking cessation.

\section{Disclosure}

The authors report no conflicts of interest in this work.

\section{References}

1. Vestbo J, Hurd SS, Agusti AG, et al. Global strategy for the diagnosis, management and prevention of chronic obstructive pulmonary disease, GOLD executive summary. Am J Respir Crit Care Med. 2013; 187(4):347-365.
2. Heron M. Deaths: leading causes for 2010. Natl Vital Stat Rep. 2013;62:1-96.

3. American Lung Association. Trends in COPD (Chronic Bronchitis and Emphysema): Morbidity and Mortality. 2010. Available from: http:// www.lung.org/finding-cures/our-research/trend-reports/copd-trendreport.pdf. Accessed September 24, 2015.

4. Ford ES, Croft JB, Mannino DM, Wheaton AG, Zhang X, Giles WH. COPD surveillance - United States, 1999-2011. Chest. 2013;144(1): 284-305.

5. Cazzola M, Bettoncelli G, Sessa E, Cricelli C, Biscione G. Prevalence of comorbidities in patients with chronic obstructive pulmonary disease. Respiration. 2010;80(2):112-119.

6. Brown DW, Pleasants R, Ohar JA, et al. Health-related quality of life and chronic obstructive pulmonary disease in North Carolina. $N \mathrm{Am}$ J Med Sci. 2010;2(2):60-65.

7. Jackson BE, Suzuki S, Coultas D, Singh KP, Bae S. Chronic obstructive pulmonary disease and health-related quality of life in the 2009 Texas Behavioral Risk Factor Survey. Health Educ Behav. 2013;40(4): 469-479.

8. Antwi S, Steck SE, Heidari K. Association between prevalence of chronic obstructive pulmonary disease and health-related quality of life, South Carolina, 2011. Prev Chronic Dis. 2013;10:E215.

9. Foster TS, Miller JD, Marton JP, Caloyeras JP, Russell MW, Menzin J. Assessment of the economic burden of COPD in the US: a review and synthesis of the literature. COPD. 2006;3(4):211-218.

10. Ford ES, Murphy LB, Khavjou O, Giles WH, Holt JB, Croft JB. Total and state-specific medical and absenteeism costs of COPD among adults aged 18 years in the United States for 2010 and projections through 2020. Chest. 2015;147(1):31-45.

11. Salvi SS, Barnes PJ. Chronic obstructive pulmonary disease in nonsmokers. Lancet. 2009;374(9691):733-743.

12. Lamprecht B, McBurnie MA, Vollmer WM, et al. BOLD Collaborative Research Group. COPD in never smokers: results from the population-based burden of obstructive lung disease study. Chest. 2011; 139(4):752-763.

13. Smith KR, Mehta S. The burden of disease from indoor air pollution in developing countries: comparison of estimates. Int J Hyg Environ Health. 2003;206:279-289.

14. Trupin L, Earnest G, San Pedro M, et al. The occupational burden of chronic obstructive pulmonary disease. Eur Respir J. 2003;22: 462-469.

15. Lomas DA, Silverman EK. The genetics of chronic obstructive pulmonary disease. Respir Res. 2001;2:20-26.

16. Forey BA, Thornton AJ, Lee PN. Systematic review with meta-analysis of the epidemiological evidence relating smoking to COPD, chronic bronchitis and emphysema. BMC Pulm Med. 2011;11:36.

17. National Heart, Lung, and Blood Institute. COPD: Are You at Risk? Available from: http://www.nhlbi.nih.gov/health/educational/copd/campaign-materials/pub/copd-atrisk.pdf. Accessed September 24, 2015.

18. Schauer GL, Wheaton AG, Malarcher AM, Croft JB. Smoking prevalence and cessation characteristics among U.S. adults with and without COPD: findings from the 2011 Behavioral Risk Factor Surveillance System. COPD. 2014;11(6):697-704.

19. Kanner RE, Connett JE, Williams DE, Buist AS. Effects of randomized assignment to a smoking cessation intervention and changes in smoking habits on respiratory symptoms in smokers with early chronic obstructive pulmonary disease: the Lung Health Study. Am J Med. 1999; 106(4):410-416.

20. Izquierdo J, Barcina C, Jimenez J, Munoz M, Leal M. Study of the burden on patients with chronic obstructive pulmonary disease. Int $J$ Clin Pract. 2009;63(1):87-88.

21. Tashkin DP. Smoking cessation in chronic obstructive pulmonary disease. Semin Respir Crit Care Med. 2015;36(4):491-507.

22. Galaznik, A, Chapnick J, Vietri J, Tripathi S, Zou KH, Makinson G. Burden of smoking on quality of life in patients with chronic obstructive pulmonary disease. Expert Rev Pharmacoecon Outcomes Res. 2013; 13(6):853-860. 
23. Global Strategy for the Diagnosis, Management and Prevention of COPD, Global Initiative for Chronic Obstructive Lung Disease (GOLD) 2013.

24. Centers for Disease Control and Prevention. Measuring Healthy Days - Population Assessment of Health-related Quality of Life. Atlanta, GA: US Centers for Disease Control and Prevention; 2000.

25. Taylor RM, Gibson F, Franck LS. A concept analysis of health-related quality of life in young people with chronic illness. J Clin Nurs. 2008; 17(14):1823-1833.

26. Stahl E, Lindberg A, Jansson SA, et al. Health-related quality of life is related to COPD disease severity. Health Qual Life Outcomes. 2005;3:56

27. Zamzam MA, Azab NY, El Wahsh RA, Ragab AZ, Allam EM. Quality of life in COPD patients. Egypt J Chest Dis Tuberc. 2013; 61(4):281-289.

28. Agrawal SR, Joshi R, Jain A. Correlation of severity of chronic obstructive pulmonary disease with health-related quality of life and six-minute walk test in a rural hospital of central India. Lung India. 2015;32(3): 233-240.

29. Abu Hassan H, Abd Aziz N, Hassan Y, Hassan F. Does the duration of smoking cessation have an impact on hospital admission and healthrelated quality of life amongst COPD patients? Int J Chron Obstruct Pulmon Dis. 2014;9:493-499.

30. Papadopoulos G, Vardavas CI, Limperi M, Linardis A, Georgoudis G, Behrakis P. Smoking cessation can improve quality of life among COPD patients: validation of the clinical COPD questionnaire into Greek. $B M C$ Pulm Med. 2011;11:13.

31. Tønnesen P, Mikkelsen K, Bremann L. Nurse-conducted smoking cessation in patients with COPD using nicotine sublingual tablets and behavioral support. Chest. 2006;130(2):334-342.
32. Centers for Disease Control and Prevention. Behavioral Risk Factor Surveillance System Operational and User's Guide. Version 3.0 2006. Available from: ftp://ftp.cdc.gov/pub/data/brfss/userguide.pdf. Accessed December 16, 2014.

33. Centers for Disease Control and Prevention. 2011 BRFSS Overview. Available from: http://www.cdc.gov/brfss/annual_data/2011/ overview_11.pdf. Accessed December 16, 2014.

34. Centers for Disease Control and Prevention. 2012 BRFSS Overview. Available from: http://www.cdc.gov/brfss/annual_data/2012/pdf/ Overview_2012.pdf. Accessed December 16, 2014.

35. Chowdhury PP, Balluz L, Strine TW. Health-related quality of life among minority populations in the United States, BRFSS 2001-2002. Ethn Dis. 2008;18:483-487.

36. Morarity DG, Zack MM, Kobau R. The Centers for Disease Control and Prevention's Healthy Days Measures - population tracking of perceived physical and mental health over time. Health Qual Life Outcomes. 2003;1(1):37.

37. Wijnhoven HAH, Kriegsman DMW, Hesselink AE, Penninx BW, deHaan M. Determinants of different dimensions of disease severity in asthma and COPD - pulmonary function and health-related quality of life. Chest. 2001;119:1034-1042.

38. Paap MC, Bode C, Lenferink LI, et al. Identifying key domains of healthrelated quality of life for patients with chronic obstructive pulmonary disease: the patient perspective. Health Qual Life Outcomes. 2014;12:106.

39. Sorheim IC, Johannessen A, Gulsvik A, Bakke PS, Silverman EK, DeMeo DL. Gender differences in COPD: are women more susceptible to smoking effects than men? Thorax. 2010;65(6):480-485.

40. Lou P, Zhu Y, Chen P, et al. Supporting smoking cessation in chronic obstructive pulmonary disease with behavioral intervention: a randomized controlled trial. BMC Fam Pract. 2013;14:91.
International Journal of COPD

\section{Publish your work in this journal}

The International Journal of COPD is an international, peer-reviewed journal of therapeutics and pharmacology focusing on concise rapid reporting of clinical studies and reviews in COPD. Special focus is given to the pathophysiological processes underlying the disease, intervention programs, patient focused education, and self management protocols.

\section{Dovepress}

This journal is indexed on PubMed Central, MedLine and CAS. The manuscript management system is completely online and includes a very quick and fair peer-review system, which is all easy to use. Visit http://www.dovepress.com/testimonials.php to read real quotes from published authors. 